\title{
Carbon monoxide-induced early thrombolysis contributes to heme oxygenase-1-mediated inhibition of neointimal growth after vascular injury in hypercholesterolemic mice
}

\author{
Yen-Hui Chen, Hui-Ling Tsai, Ming-Tsai Chiang \& Lee-Young Chau* \\ Institute of Biomedical Sciences, Academia Sinica, Taipei, 11529, Taiwan, Republic of China \\ Received 21 February 2006; accepted 22 May 2006 \\ (C) 2006 National Science Council, Taipei
}

Key words: heme oxygenase, thrombolysis, vascular injury

\begin{abstract}
Arterial thrombosis is a critical event in the pathogenesis of lesion development. In this study, we evaluated the effect of heme oxygenase-1 (HO-1), a stress-inducible enzyme with vasoprotective functions, on arterial thrombosis following vascular mechanical injury. The carotid arteries of apoE-deficient mice were subjected to angioplasty with a modified beaded-needle. Arterial thrombosis occurred at $12 \mathrm{~h}$ after injury. Treatment of the injured vessels with an adenovirus bearing HO-1 gene (Adv-HO-1) $\left(1 \times 10^{8} \mathrm{pfu}\right)$, but not saline or empty adenovirus (Adv), immediately after angioplasty resulted in earlier thrombolysis and restoration of blood flow detected at $24 \mathrm{~h}$. Immunohistochemistry revealed that the arterial plasminogen activator inhibitor-1 (PAI-1) expression was markedly reduced in Adv-HO-1-treated injured arteries as compared to control counterparts. The thrombolytic effect was also observed by exposing animals with existing arterial thrombosis to carbon monoxide (CO) $(250 \mathrm{ppm}, 2 \mathrm{~h})$, a byproduct derived from heme degradation by HO-1. In parallel with less fibrin(ogen) deposition, the macrophage infiltration, monocyte chemoattractant protein-1 expression and neointimal formation assessed at 2 weeks after angioplasty were substantially reduced in injured arteries treated with Adv-HO-1. These results support a role of early thrombolysis induced by $\mathrm{CO}$ in $\mathrm{HO}-1$-mediated protection against intimal hyperplasia after vascular injury.
\end{abstract}

\section{Introduction}

Heme oxygenase-1 (HO-1) is a stress-inducible enzyme catalyzing the degradation of heme to liberate free iron, carbon monoxide $(\mathrm{CO})$ and biliverdin, the last of which is subsequently converted to bilirubin by bilirubin reductase [1]. Over the past few years, numerous studies have supported the vital role of $\mathrm{HO}-1$ in protecting vascular functions. Overexpression of HO-1 in arterial walls has been shown to reduce lesion formation and intimal hyperplasia subsequent to vascular injury in animals [2-5]. Several mechanisms were consid-

*To whom correspondence should be addressed. Fax: + 886-22785-8847; E-mail: lyc@ibms.sinica.edu.tw ered to participate in the vasoprotection conferred by HO-1. It has been shown that bilirubin can act as an antioxidant to inhibit monocyte adhesion and transmigration through endothelium [6]. CO, like nitric oxide, can activate guanylate cyclasecGMP pathway, which in turn elicits vasodilation and inhibits platelet activation and smooth muscle cell proliferation [3, 7]. More recently, studies also demonstrated that $\mathrm{CO}$ exerts potent anti-inflammatory and anti-apoptotic activities [1].

Arterial thrombosis following vascular injury or plaque rupture is a critical event in the pathogenesis of several cardiovascular diseases, including restenosis, unstable angina pectoris, myocardial infarction, and stroke [8]. It is a complex process influenced by coagulation and 
fibrinolytic pathways [9, 10], inflammation [11], and hypercholesterolemic state [12]. The first line of evidence supporting the anti-thrombotic effect of $\mathrm{HO}-1$ in vivo is the observation that $\mathrm{CO}$ suppressed vascular thrombosis occurring during the cardiac graft rejection likely through inhibiting platelet aggregation [13]. Subsequently, there was a study showing that $\mathrm{CO}$ protected ischemic lung injury through down regulating the expression of plasminogen activator inhibitor-1 (PAI-1), the principal regulator of the fibrinolytic system, in macrophages and derepressing fibrinolysis [14]. Whether the similar anti-thrombotic effect has a role in HO-1-mediated protection in the setting of intimal hyperplasia following vascular mechanical injury remains to be established. To address this issue, in the present study we applied an injury model by performing angioplasty in the carotid arteries of the hypercholesterolemic animals, apoE-deficient mice. The effect of adenovirusmediated HO-1 transduction on the thrombotic response of injured vessels was assessed. Moreover, additional experiment was performed to elucidate the potential role of $\mathrm{CO}$ in this process.

\section{Methods}

\section{Carotid injury and thrombosis}

$\mathrm{ApoE}^{-/-}$mice were purchased from the Jackson laboratory, bred and maintained in a specific pathogen free housing facility. Male mice (6-10weeks old, $25.8 \pm 1.8 \mathrm{~g}$ ) were used in this study. Animals were anesthetized intramuscularly with a combination of ketamine $8 \mathrm{mg} / 100 \mathrm{~g}$ body weight, xylazine $2 \mathrm{mg} / 100 \mathrm{~g}$, and atropine $0.16 \mathrm{mg} / 100 \mathrm{~g}$. The right carotid artery was exposed and the endothelial denudation of the common carotid was induced with a 29 Gauge needle $(0.35 \mathrm{~mm}$ in diameter) on which the tip was roughed and coated with a $\alpha$-cyanoacrylate bead $(0.5 \mathrm{~mm}$ in diameter). This modified needle was then introduced through the internal carotid artery and moved into the common carotid artery. The common carotid artery was abraded 4 times. Immediately after injury, $10 \mu 1$ of saline or viral vector $\left(1 \times 10^{8} \mathrm{pfu}\right)$ was injected into the lumen of the operated artery. After $10 \mathrm{~min}$ incubation, the arteriotomy site was ligated and skin was closed using suture. For detecting thrombus formation, the carotid blood flow was measured using an ultrasound unit (ATL HDI 5000, SonoCT) with a $15 \mathrm{MHz}$ linear transducer. Animals were anesthetized by intraperitoneal injection of Avertin (25 mg/100 g body weight). The systolic velocity of carotid blood flow was measured 3 times and the average was recorded. The handling of animals and experimental procedures were approved by the Institutional Animal Care and Utilization Committee of Academia Sinica.

\section{Preparation of recombinant adenovirus}

Recombinant adenovirus containing human HO-1 (Adv-HO-1) gene was prepared as described previously [4].

\section{CO exposure}

At $12 \mathrm{~h}$ after vascular injury, animals were placed in chamber ( 1.385 cubic $\mathrm{ft})$ containing room air or $250 \mathrm{ppm}$. CO gas for $2 \mathrm{~h}$. The concentration of CO in the chamber was continuously monitored by a gas monitor (Bacharach, New Kensington, USA).

\section{Histology}

The operated carotid arteries were excised, fixed in $4 \%$ paraformaldehyde, embedded in paraffin, and serially sectioned at $7 \mu \mathrm{m}$ for histological staining or other experiments.

\section{Western blot analysis}

Vascular tissue was homogenized in phosphatebuffered saline (PBS) containing 1\% Tritin X-100, $0.1 \%$ SDS, $0.5 \%$ sodium deoxycholate, $1 \mathrm{mM}$ EDTA, and $1 \mathrm{mM}$ phenylmethylsulfonyl fluoride. After centrifugation at $12,000 \mathrm{rpm}$ for $20 \mathrm{~min}$ at $4{ }^{\circ} \mathrm{C}$, the supernatant was removed and protein concentration was determined by Bio-Rad protein assay. Fifty $\mu \mathrm{g}$ of proteins was electrophoresed on $10 \%$ SDS-polyacrylamide gel and the transblotted onto the Immobilon ${ }^{\mathrm{TM}}-\mathrm{P}$ membrane (Millipore). Western blot analysis was carried out as describe previously [4].

\section{Lesion quantification}

Animals were killed at 2 weeks after vascular injury. Totally 80 sections from each injured artery were 
collected. Total 9 sections sampled from every 10 consecutive sections were stained with Verhoeff van Gieson elstic stain and used for lesion estimation. The thickness of intima and media was measured in 8 directions, in which the interval of every two directions was $45^{\circ}$ and the average was taken. Intima/ media ratio was defined as the ratio between the thickness of neointima and the thickness of media.

\section{Immunohistochemistry}

Immunostaining was carried out using the following antibodies: rabbit anti-HO-1 polyclonal antibody (StressGen), rabbit anti-PAI-1 polyclonal antibody (Santa Cruz), goat anti-MCP-1 polyclonal antibody (Santa Cruz), rabbit anti-mouse macrophage polyclonal antibody (AIA31240) (Accurate), rabbit anti-fibrin(ogen) polyclonal antibody (Dako). Tissue sections were pretreated with 3\% $\mathrm{H}_{2} \mathrm{O}_{2}$ for $15 \mathrm{~min}$ at room temperature. After incubation in phosphate-buffered saline (PBS) containing $2 \%$ bovine serum albumin (BSA) at $37{ }^{\circ} \mathrm{C}$ for $30 \mathrm{~min}$, sections were incubated with primary antibody at $37^{\circ} \mathrm{C}$ for $30 \mathrm{~min}$, followed by 3 washes in PBS. Sections were then incubated with horseradish peroxidase-conjugated secondary antibody for another $30 \mathrm{~min}$. After 3 washes, color was developed with $0.1 \% 3,3^{\prime}$-diaminobenzidine. The pictures were taken in $200 \times$ magnification using a CCD camera (Olympus, DP70) attached to a microscope system (Olympus, BX51).

The software "Image-Pro Plus (Media Cybernetics, Silver Spring, USA)" was used to detect the HO-1 and PAI-1 expression level. Manual gray scale thresholding was performed for quantification of the expression area in the vessel wall.

\section{Statistical analysis}

Data were expressed as mean \pm SD. Grouped data were analyzed by ANOVA followed by TukeyKramer's test. A value of $p<0.05$ was considered statistically significant.

\section{Results}

Effect of HO-1 gene transfer on thrombotic response to arterial injury in apoE-deficient mice

Hypercholesterolemia has been shown to influence the arterial thrombotic response after injury [12].
To use an animal model similar to the pathophysiological setting in humans, the apoE-deficient mice, which develop hypercholesterolemia at young age, were chosen for the study. These mice were subjected to angioplasty induced by a modified beaded-needle. We found that the thrombotic occlusion occurred in the carotid arteries at $12 \mathrm{~h}$ after injury in over $95 \%$ of animals examined (Figure 1). The thrombus was not dissolved at $24 \mathrm{~h}$ in the injured arteries treated with saline. Examination of injured arteries by spectrum Doppler also demonstrated that the blood flow was significantly reduced at $12 \mathrm{~h}$ after injury in saline-treated control (Table 1). At $24 \mathrm{~h}$, the blood flow was barely restored. Infection of injured arteries with control empty $\mathrm{Adv}\left(1 \times 10^{8} \mathrm{pfu}\right)$ immediately after angioplasty did not significantly affect the thrombotic response. When the injured arteries were infected with Adv-HO- $1\left(1 \times 10^{8} \mathrm{pfu}\right)$, the thrombosis was also detected at $12 \mathrm{~h}$ after the angioplasty. Nevertheless, the extent of occlusion was not so severe as compared to that in saline(control) or Adv-treated counterparts (Figure 1). Consistently, the blood flow velocity of the AdvHO-1-treated injured vessels determined at the same time point was also higher than the counterparts $(p<0.01)$. Interestingly, complete thrombolysis was observed and blood flow restored in the Adv-HO-1-treated vessels at $24 \mathrm{~h}$ after vascular injury.

Effect of HO-1 on PAI-1 expression and fibrin(ogen) deposition in arterial walls after injury

PAI-1 expression has been shown to participate in the thrombotic response following vascular injury by preventing thrombus dissolution [15-17]. As shown in Figure 2A, PAI-1 expression examined by immunohistochemistry was not observed in the uninjured artery. In contrast, angioplasty significantly induced PAI-1 expression in medial smooth muscle cells as early as $6 \mathrm{~h}$ and lasted at least for $24 \mathrm{~h}$ after injury. The arterial PAI-1 induction was also detected at $6 \mathrm{~h}$ in injured arteries infected with Adv-HO-1. However, it was markedly reduced at later time points in Adv-HO-1-treated arteries. When the expression of HO-1 in the injured vessels infected with Adv-HO-1 was examined, it was found that HO-1 was not yet detected at $6 \mathrm{~h}$ after the gene delivery, but became evident at later time 


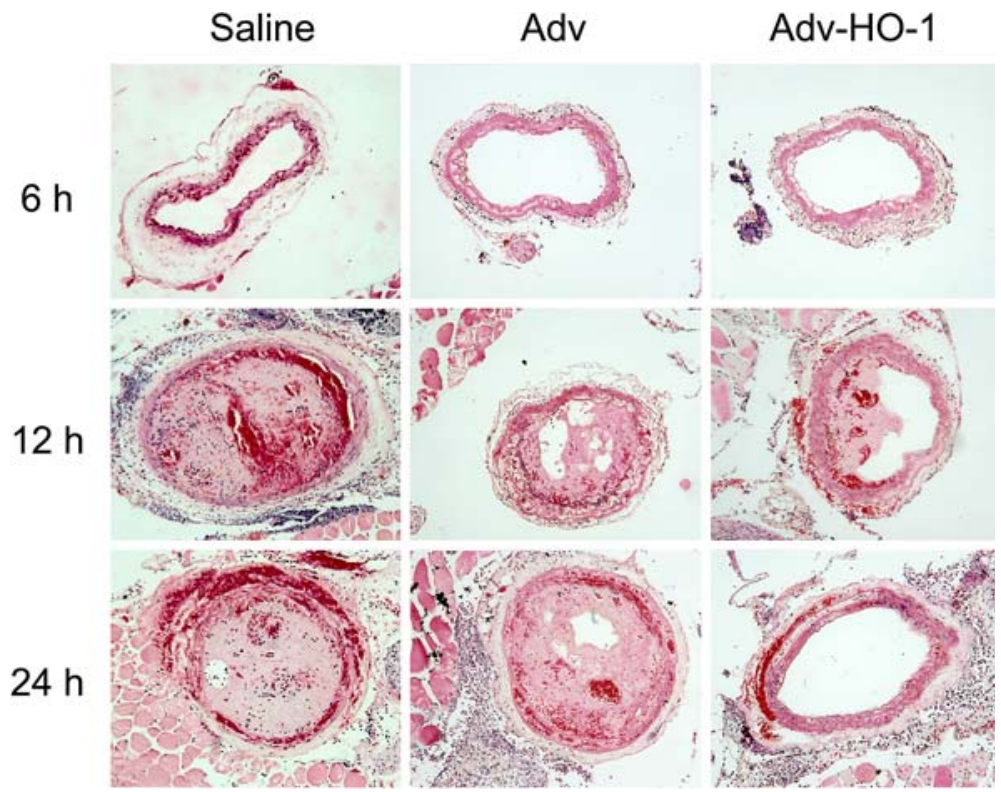

Figure 1. Effect of HO-1 gene transfer on arterial thrombosis after needle-induced injury in carotid arteries of apoE-deficient mice. The carotid arteries were subjected to angioplasty and subsequent treatment with saline or $1 \times 10^{8}$ pfu of Adv or Adv-HO-1. At indicated times after the injury, the vessel segments were removed and examined by $\mathrm{H} \& \mathrm{E}$ staining.

points (12 $\mathrm{h}$ and $24 \mathrm{~h})$ (Figure 2B). These observations indicate that the arterial PAI-1 expression was down- regulated following $\mathrm{HO}-1$ overexpression. Further experiment was performed to examine the fibrin(ogen) deposition in the injured arteries. As shown in Figure 3, positive immunoreactivities to fibrin(ogen) was prominent in the thrombi and arterial walls of saline or Advtreated injured vessels at 1 day after angioplasty. The fibrinogen deposition remained detectable in the saline or Adv-treated injured vessels at 2 week after the injury. In contrast, HO-1 gene transfer markedly reduced the intravascular fibrin(ogen) deposition in injured vessels examined at 1 day and 2 weeks after angioplasty.

\section{Role of $\mathrm{CO}$ in HO-1-mediated thrombolysis and suppression of PAI-1 expression}

$\mathrm{CO}$ has been shown to mediate in large part the antiproliferative effect of HO-1 after vascular injury in experimental animals $[2,3,5]$. To examine the role of $\mathrm{CO}$ in $\mathrm{HO}-1$-induced thrombolysis, mice receiving angioplasty for $12 \mathrm{~h}$ were exposed to room

Table 1. Effect of local HO-1 gene transfer on blood flow velocities $(\mathrm{cm} / \mathrm{sec})$ of injured carotid arteries after angioplasty in apoEdeficient mice.

\begin{tabular}{|c|c|c|c|c|c|c|}
\hline \multirow{2}{*}{$\begin{array}{l}\text { Treatment } \\
\text { Time post-angioplasty }\end{array}$} & \multicolumn{2}{|l|}{ Saline } & \multicolumn{2}{|l|}{$\mathrm{Adv}$} & \multicolumn{2}{|l|}{ Adv-HO-1 } \\
\hline & Uninjured & Injured & Uninjured & Injured & Uninjured & Injured \\
\hline $6 \mathrm{~h}(n=5)$ & $37.8 \pm 3.8$ & $38.4 \pm 6.8$ & $37.6 \pm 4.4$ & $31.5 \pm 9.0$ & $35.7 \pm 5.1$ & $30.8 \pm 10.2$ \\
\hline $12 \mathrm{~h}(n=10)$ & $38.6 \pm 3.6$ & $9.1 \pm 8.3^{*}$ & $38.7 \pm 3.5$ & $9.8 \pm 8.3^{*}$ & $37.5 \pm 5.5$ & $19.9 \pm 7.4^{* *}$ \\
\hline $24 \mathrm{~h}(n=5)$ & $40.6 \pm 4.8$ & $14.6 \pm 9.5^{*}$ & $43.0 \pm 13.9$ & $19.1 \pm 5.7^{*}$ & $45.1 \pm 8.4$ & $45.9 \pm 7.7$ \\
\hline
\end{tabular}

The apoE-deficient mice were anesthetized and the right carotid arteries were subjected to angioplasty as described in Methods. Immediately after injury, $10 \mu \mathrm{l}$ of saline or viral vector $\left(1 \times 10^{8} \mathrm{pfu}\right)$ was injected into the operated arteries and incubated for $10 \mathrm{~min}$. The arteriotomy sites were then ligated and skins closed using suture. At indicated time points after the operation, the blood flow velocities of both uninjured (left) and injured carotid arteries in each animal were examined using an ultrasound unit (ATL HDI 5000, SonoCT) with a $15 \mathrm{MHz}$ linear transducer. The numbers of animals in each group are indicated in parentheses. ${ }^{*} p<0.001$ vs uninjured arteries; $* p<0.01$ vs saline or Adv-treated injured arteries. 

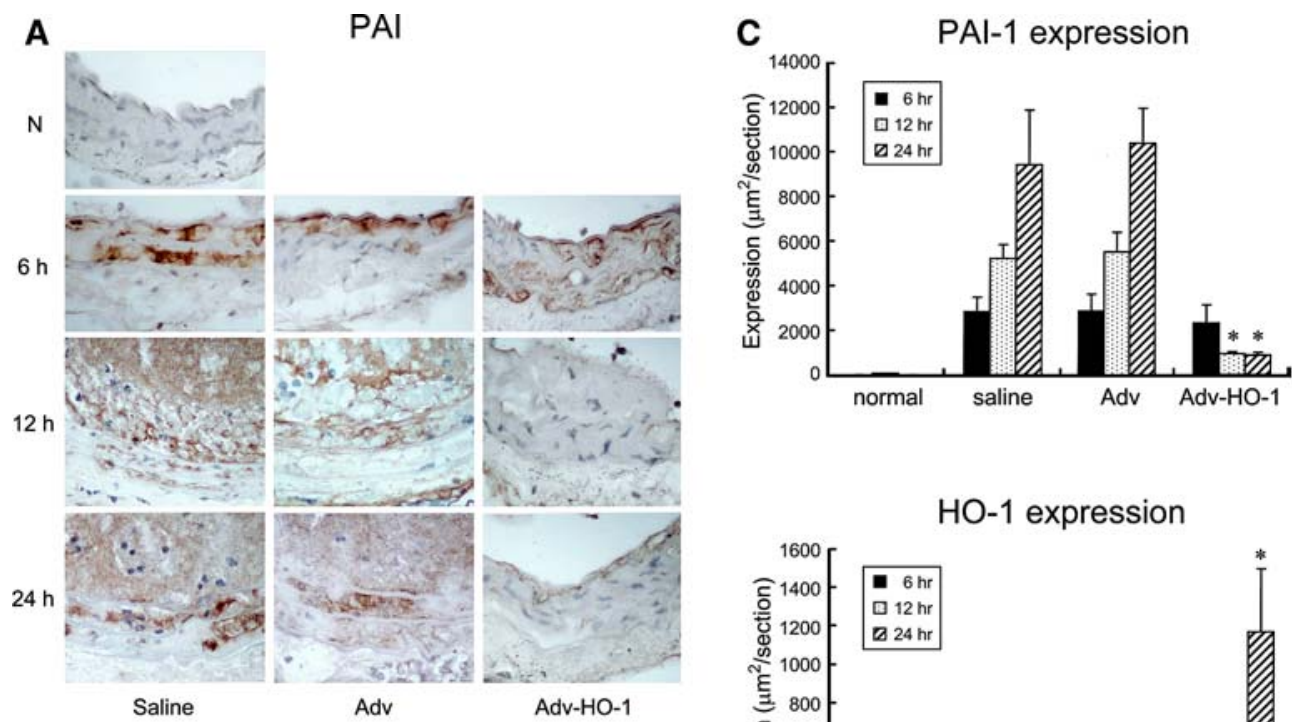

B

$\mathrm{HO}-1$
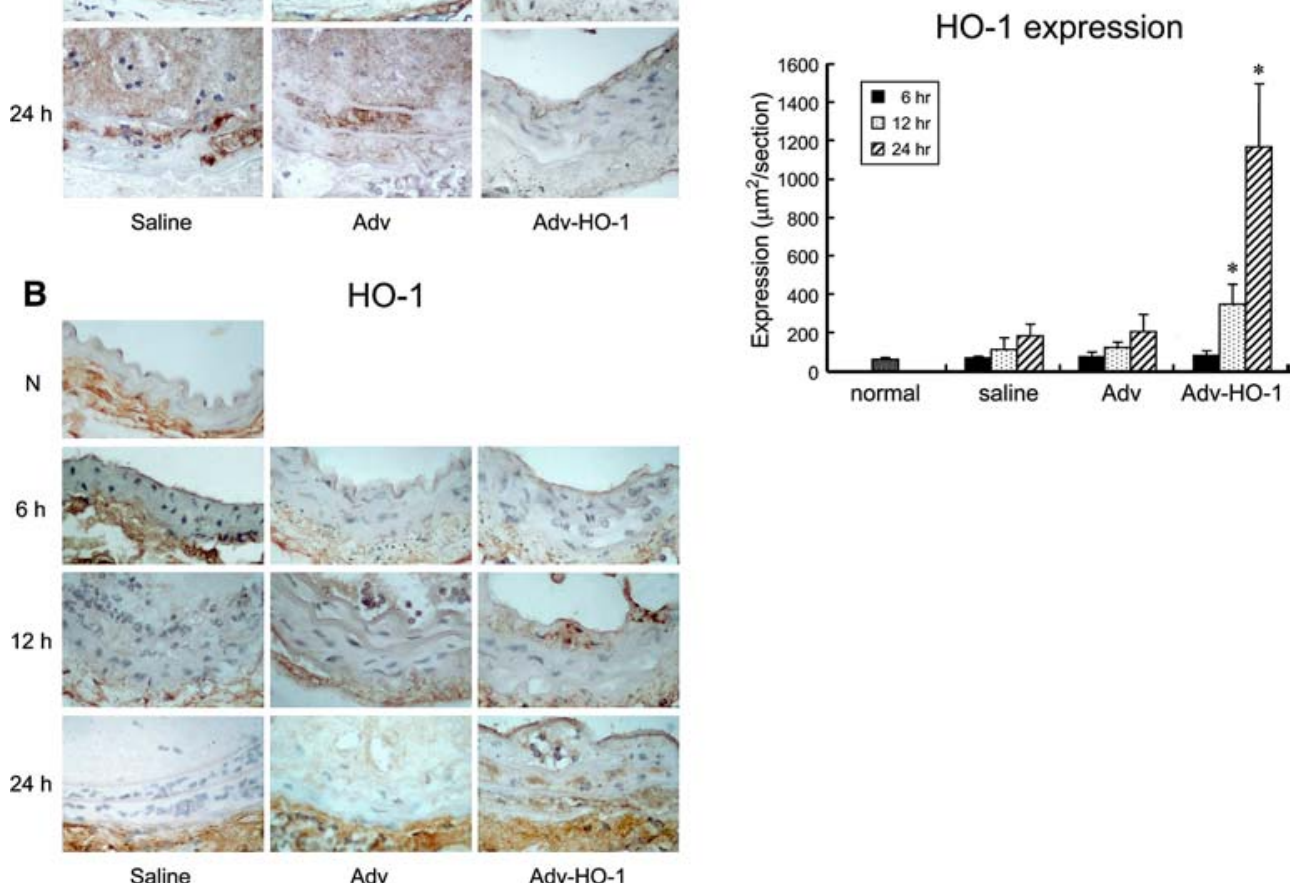

Figure 2. Inverse association between HO-1 expression and PAI-1 induction in injured arterial walls. The carotid arteries of apoEdeficient mice were subjected to angioplasty and subsequent treatment with saline or $1 \times 10^{8}$ pfu of Adv or Adv-HO-1. A, At indicated times after the injury, the PAI-1 expression on injured arterial segments were examined by immunostaining with specific antibody against PAI-1 (A) or HO-1 (B). $\mathrm{N}$ is the uninjured arterial segment. The quantitative results of the immunostains were shown in $\mathrm{C}$. The numbers of animals in each group are five. ${ }^{*} p<0.05$ vs saline or Adv-treated group.

air or $250 \mathrm{ppm} \mathrm{CO}$ gas for $2 \mathrm{~h}$, and the blood flow and thrombus were then examined at $10 \mathrm{~h}$ later. The results clearly showed that short term $\mathrm{CO}$ exposure completely restored the blood flow of injured vessels back to the level comparable to uninjured counterparts $\quad(47.8 \pm 7.2 \mathrm{~cm} / \mathrm{sec}$ vs $39.7 \pm 1.8 \mathrm{~cm} / \mathrm{sec}$, $n=5$ ). In contrast, the blood flow velocity of injured vessels of animals exposed to room air remained significantly lower than that of injured counterparts $(14.8 \pm 7.8 \mathrm{~cm} / \mathrm{sec}$ vs $45.1 \pm 6.3 \mathrm{~cm} /$ sec; $n=5, p<0.001)$. Consistently, $\mathrm{H} \& \mathrm{E}$ staining of arterial sections revealed completely dissolution of thrombus in CO-treated animals (Figure 4A). Likewise, immunohistochemistry and Western blot analysis revealed that arterial PAI-1 expression in the injured vessels was also suppressed by $\mathrm{CO}$ treatment (Figure 4B). These findings clearly indicate that $\mathrm{CO}$ mediates the anti-thrombotic effect of HO-1 at least in part through inhibiting arterial PAI-1 expression following injury. 


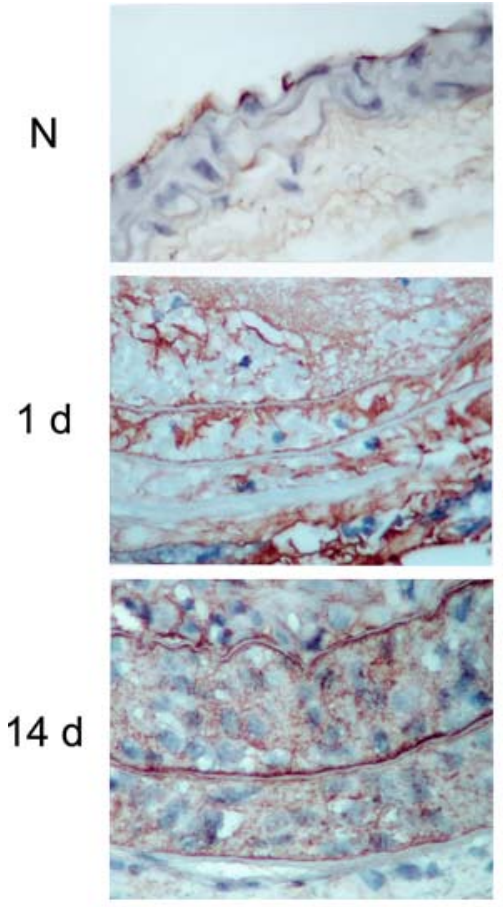

Saline
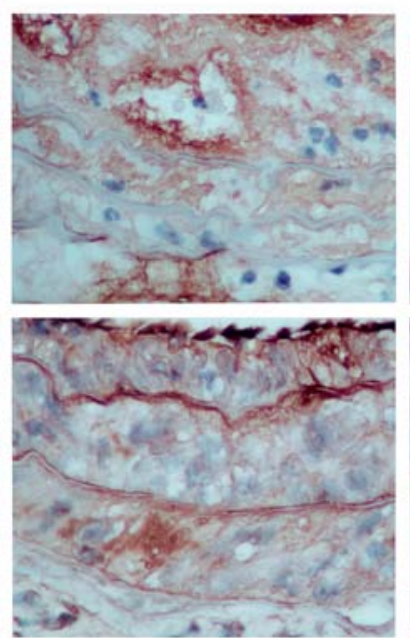

Adv
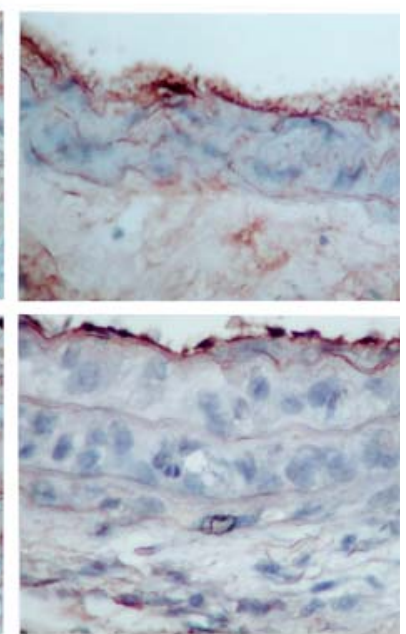

Adv-HO-1

Figure 3. Effect of HO-1 on fibrin(ogen) deposition in injured arterial walls. The carotid arteries of apoE-deficient mice were subjected to angioplasty and subsequent treatment with saline or $1 \times 10^{8} \mathrm{pfu}$ of Adv or Adv-HO-1. At 1 day and 14 days after the injury, the fibrin(ogen) deposition was examined by immunostaining with specific antibody against fibrin(ogen). $\mathrm{N}$ is the uninjured arterial segment.

\section{HO-1-mediated inhibition on injury-induced inflammation and neointimal formation}

As fibrin deposited in vessels promotes inflammatory response and smooth muscle cell proliferation, we then examined the neointimal formation in the injured arteries at 2 weeks after angioplasty. As shown in Figure 5A and B, Adv-HO-1 infection significantly suppressed neointimal growth in injured arteries in apoEdeficient mice. Immunostaining illustrated that monocyte chemoattractant protein-1 (MCP-1) expression and macrophage infiltration, the indices of inflammation, was prominent in saline or Adv-treated injured arteries, but not in Adv-HO1-treated counterparts (Figure 5C). These results support that the local HO-1 gene transfer in injured vessels prevents inflammatory response and neointimal hyperplasia developed in hypercholesterolemic animals.

\section{Discussion}

Thrombosis is a critical event implicated in the vascular remodeling after vascular injury. Earlier reports by several groups have shown that HO-1 overexpression prevented neointimal formation following vascular injury in normocholesterolemic animals $[2-5,18,19]$. In those studies, CO-mediated inhibition of smooth muscle cell proliferation and induction of apoptosis was considered to be the primary mechanism underlying the protective effect of HO-1. However, it remained unclear whether HO-1 can affect the early thrombotic reaction at sites of vascular injury and impact the subsequent remodeling events in the hypercholesterolemic state, which is more relevant to the clinical situation. To clarify the issue, in the present study we employed a modified mechanical injury model to induce arterial thrombotic occlusion in apoE-deficient mice. As revealed by the 


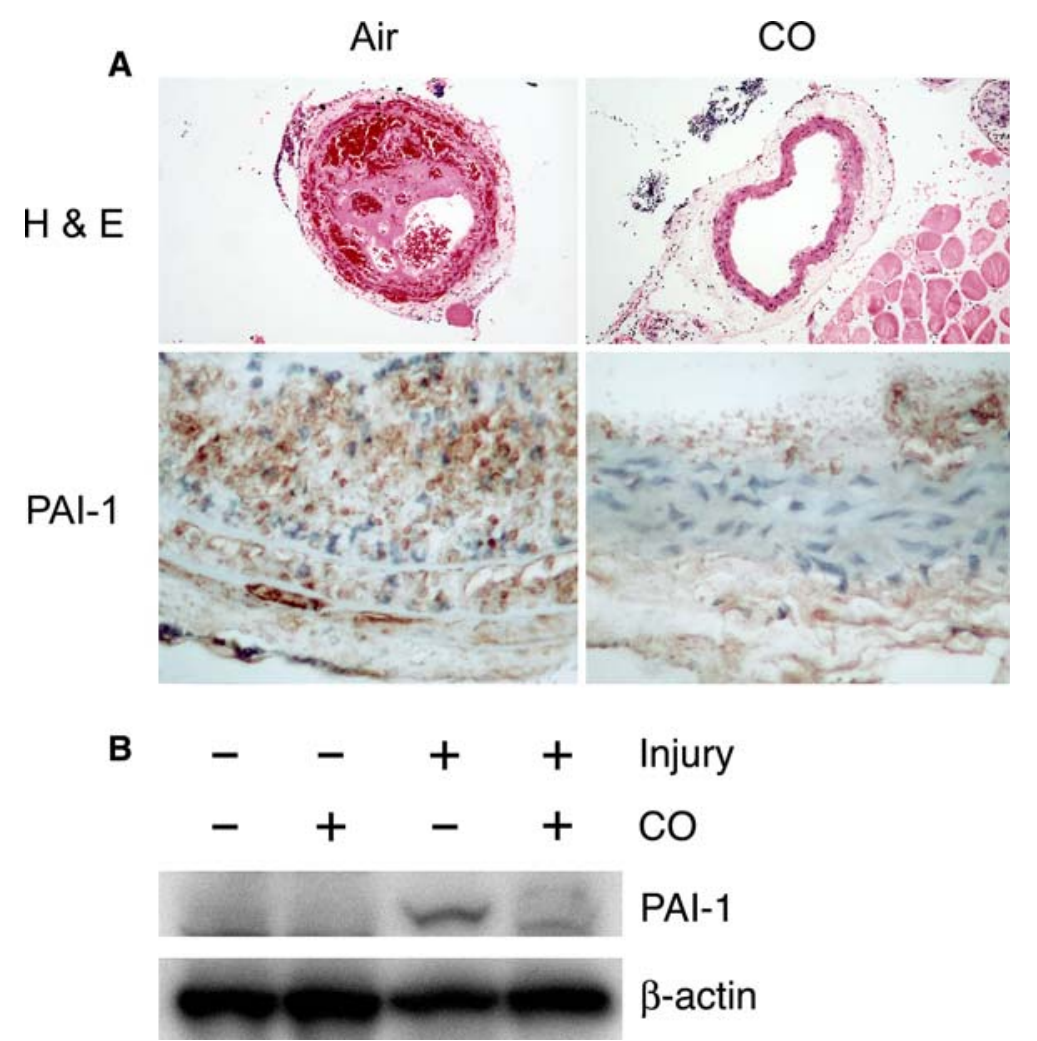

Figure 4. Effect of $\mathrm{CO}$ exposure on thrombolysis. The apoE-deficient mice received angioplasty for $12 \mathrm{~h}$, followed by exposure to room air or $250 \mathrm{ppm} \mathrm{CO}$ for $2 \mathrm{~h}$. (A) Animals were sacrificed at $10 \mathrm{~h}$ later and the injured arterial segments were subjected to histological examination or immunostaining with specific antibody against PAI-1. (B) The uninjured and injured carotid arteries from each treated group of animals ( $n=5$ in each group) were separately collected. Tissue homogenates were then prepared and the expression of PAI-1 protein examined by Western blot analysis as described in Methods.

histological assessment and the measurement of blood flow velocity by spectrum Doppler, local adenovirus-mediated HO-1 gene transfer immediately following angioplasty in injured vessels did not prevent thrombosis; whereas it suppressed the thrombus formation to a certain extent as compared to that of counterparts treated with empty adenovirus. This finding appears to be consistent with a recent study showing that systemic induction of HO-1 by prior treatment of animals with heme suppressed microvascular thrombus formation subsequent to $\mathrm{FeCl}_{3}$-induced vascular injury [20]. In that study, the anti-oxidant activity of bilirubin was shown to mediate the anti-thrombotic property of HO-1 through down regulating the expression of P-selectin. Although we did not further investigate the pathways leading to the suppressed arterial thrombus formation by HO-1 gene delivery in the present experimental setting, it is reasonable to consider that the anti-platelet activity of $\mathrm{CO}$ as well as the suppressive effect of bilirubin on P-selectin expression may participate in this process.

When we further examined the thrombolytic event at the later time points, it was noted that the saline- or Adv-treated injured vessels remained seriously occluded at $24 \mathrm{~h}$ after vascular injury. In contrast, the blood flows of Adv-HO-1-treated injured arteries were completely restored at the same time point, indicating that HO-1 overexpression facilitated the dissolution of thrombus. Immunohistochemistry clearly showed that the local HO-1 expression was associated with the down regulation of arterial PAI-1 expression and reduced fibrin deposition in injured vascular walls. Concordant with the present observation, previous studies have shown that increased circulating level of PAI-1 is a risk factor for myocardial infarction and restenosis in human patients [21-23]. Furthermore, up-regulation of PAI-1 expression 
A

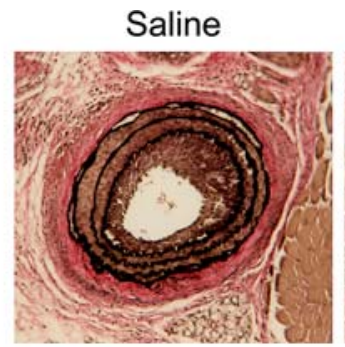

Adv

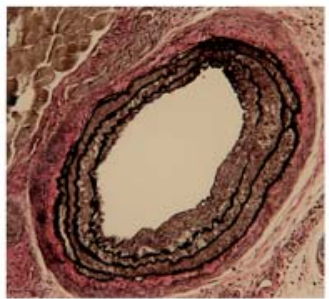

Adv-HO-1

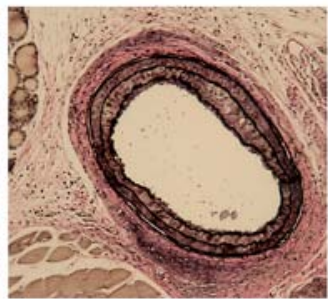

B

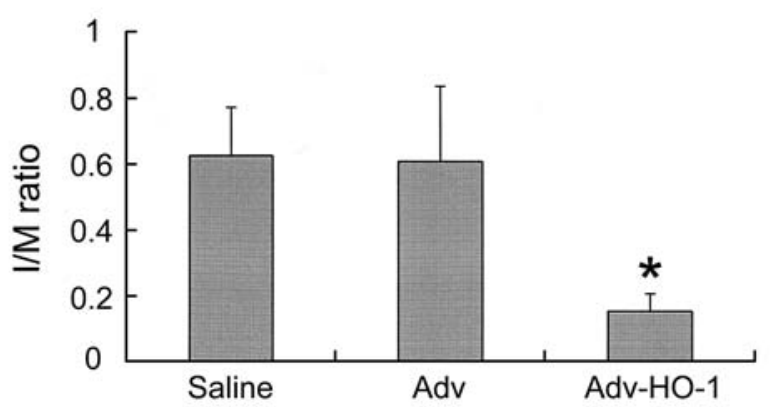

C

N

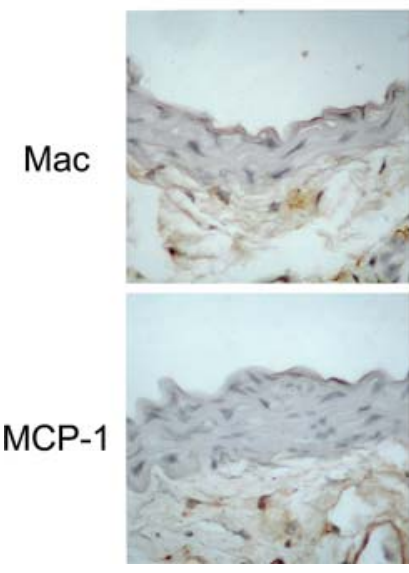

Adv
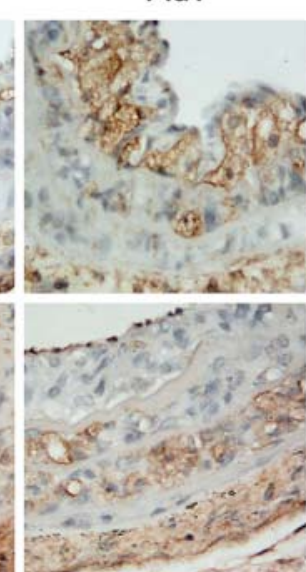

Adv-HO-1

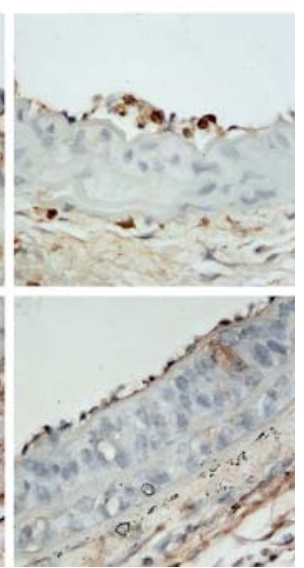

Figure 5. Effect of HO-1 gene transfer on neointimal formation and inflammatory response. The carotid arteries of apoE-deficient mice were subjected to angioplasty and subsequent treatment with saline or $1 \times 10^{8}$ pfu of Adv or Adv-HO-1. At 2 weeks after the injury, the neointimal formation was examined. (A) The Verhoeff van Gieson stains of injured arterial segments. (B) The intima/ media $(\mathrm{I} / \mathrm{M})$ ratios of the injured arteries in various treated groups. The thickness of intima and media of injured arteries was quantified as described in Methods. The numbers of animals in each group are eight. ${ }^{*} p<0.001$ vs saline or Adv-treated group. (C) The extents of macrophage infiltration and the expression of MCP-1 were examined by immunostaining with specific antibodies against macrophage surface marker and MCP-1, respectively.

has been demonstrated in human atherosclerotic lesions of arteries [24] and failed vein grafts [25], and in neointima after vascular injury in experimental animals [26]. Over the past few years, the pathophysiological role of PAI-1 in the vascular remodeling process underlying atherosclerosis and restenosis have been extensively studied in mouse models with PAI-1 deficiency or overexpression
[15-17, 27-29]. Although there were some reports showing that local PAI-1 overexpression inhibits lesion formation [27, 28], more studies demonstrated that PAI-1 promotes neointimal formation after vascular injury, which is through stabilizing thrombus formation and fibrin deposition in injured arteries [15-17, 29]. Apparently, the present data provide an additional piece of evidence to 
support the detrimental role of PAI-1 in the vascular remodeling. Further experiments demonstrated that $\mathrm{CO}$ exhibited similar suppressive effect on PAI-1 expression in injured vessels, indicating that $\mathrm{CO}$ mediates the effect of HO-1. A study by Otterbein et al. has demonstrated that $\mathrm{CO}$ could prevent vascular injury associated with chronic graft rejection without affecting the arterial PAI-1 expression [18]. It is speculative that $\mathrm{CO}$ may exhibit differential effects on arterial PAI-1 expression induced by various insults. However, further studies are required to test this possibility.

Considerable evidence has supported the role of fibrin generated following coagulation activation in the recruitment of inflammatory cells, promotion of vascular proinflammatory cytokine response and proliferation of smooth muscle cells in injured vessels [30]. We noted that the positive immunoreactivities for fibrin(ogen) remained prominent in the media of saline- or Adv-treated injured arteries, but not Adv-HO-1-treated counterparts, at 2 weeks after injury, which was associated with significant neointimal formation examined at the same time point. When the extents of macrophage infiltration and the expression of MCP-1, the indices of inflammation, in the injured arterial segments were examined, it was found that HO-1 gene delivery significantly reduced the number of macrophages and the chemokine expression in injured vascular walls. Although HO-1-mediated anti-inflammatory and anti-proliferative effects may participate directly in the inhibition of inflammation and neointimal growth in injured vessels, the protection resulted from the suppression on thrombotic response and fibrin deposition cannot be overlooked. In any event, our present study demonstrated that local HO-1 gene delivery in arterial injured sites conferred multiple vasoprotective effects. HO-1-mediated suppression of arterial PAI-1 expression results in the reduced deposition of fibrin(ogen) in injured vascular walls, which contributes at least in part to the decreased inflammatory response and neointimal development at later phase. As arterial thrombosis remains as one of the most serious complications after percutaneous coronary intervention in human patients, the anti-thrombotic effect of HO-1 apparently increases its therapeutic potential as a gene target for treating the thrombosis-related vascular diseases.

\section{Acknowledgements}

This work was supported by the Genomic Research Grant from Academia Sinica of Taiwan (91IBMS3PP-H).

\section{References}

1. Otterbein L.E. and Choi A.M.K., Heme oxygenase: colors of defense against cellular stress. Am. J. Physiol. 279: L1029-1037, 2000.

2. Aizawa T., Ishizaka N., Taguchi J., Kimura S., Kurokawa K. and Ohno M., Balloon injury does not induce heme oxygenase-1 expression, but administration of hemin inhibits neointimal formation in balloon-injured rat carotid artery. Biochem. Biophys. Res. Commun. 261: 302-307, 1999.

3. Duckers H.J., Boehm M., True A.L., Yet S.F., San H., Park J.L., Clinton Webb R., Lee M.E., Nabel G.J. and Nabel E.G., Heme oxygenase-1 protects against vascular constriction and proliferation. Nat. Med. 7: 693-698, 2001.

4. Juan S.H., Lee T.S., Tseng K.W., Liou J.Y., Shyue S.K., Wu K.K. and Chau L.Y., Adenovirus-mediated heme oxygenase gene transfer inhibits the development of atherosclerosis in apolipoprotein E-deficient mice. Circulation 104: 1519-1525, 2001.

5. Togane Y., Morita T., Suematsu M., Ishimura Y., Yamazaki J.I. and Katayama S., Protective roles of endogenous carbon monoxide in neointimal development elicited by arterial injury. Am. J. Physiol. Heart Circ. Physiol. 278: H623-H632, 2000.

6. Ishikawa K., Navab M., Leitinger N., Folelman A.M. and Lusis A.J., Inhibition of heme oxygenase-1 inhibits the monocyte transmigration induced by mildly oxidized LDL. J. Clin. Invest. 100: 1209-1216, 1997.

7. Brune B. and Ullrich V., Inhibition of platelet aggregation by carbon monoxide is mediated by activation of guanylate cyclase. Mol. Pharmacol. 32: 497-504, 1987.

8. Fuster V. and Lewis A., Conner memorial lecture: mechanisms leading to myocardial infarction:insights from studies of vascular biology. Circulation 90: 2126-2146, 1994.

9. Dobrovolsky A.B. and Titaeva E.V., The fibronolysis system: regulation of activity and physiologic functions of its main components. Biochemistry (Mosc) 67: 99-108, 2002.

10. Spronk H.M., Govers-Riemslag J.W. and ten Cate H., The blood coagulation system as a molecular machine. Bioessays 25 : $1220-1228,2003$.

11. Levi M., Keller T.T., van Gorp E. and ten Cate H., Infection and inflammation and the coagulation system. Cardiovasc. Res. 60: 26-39, 2003.

12. Eitzman D.T., Westrick R.J., Xu Z., Tyson J. and Ginsburg D., Hyperlipidemia promotes thrombosis after injury to atherosclerotic vessels in apolipoprotein E-deficient mice. Arterioscler. Thromb. Vas. Biol. 20: 1831-1834, 2000.

13. Sato K., Balla J., Otterbein L., Smith R.N., Brouard S., Lin Y., Csizmadia E., Sevigny J., Robson S.C., Vercellotti G., Choi A.M., Bach F.H. and Soares M.P., Carbon monoxide generated by heme oxygenase-1 suppresses the rejection of 
mouse-to-rat cardiac transplants. J. Immunol. 166: 41854194, 2001.

14. Fujita T., Toda K., Karimova A., Yan S.F., Naka Y., Yet S.F. and Pinsky D.J., Paradoxical rescue from ischemic lung injury by inhaled carbon monoxide driven by derepression of fibrinolysis. Nat. Med. 7: 598-604, 2001.

15. Farrehi P.M., Ozaki K., Carmeliet P. and Fay W.P., Regulation of arterial thrombolysis by plasminogen activator inhibitor-1 in mice. Circulation 97: 1002-1008, 1998.

16. Konstantinides S., Schäfer K., Thinnes T. and Loskutoff D.J., Plasminogen activator inhibitor-1 and its cofactor vitronectin stabilize arterial thrombi after vascular injury in mice. Circulation 103: 576-583, 2001.

17. Schäfer K., Müller K., Hecke A., Mounier E., Goebel J., Loskutoff D.J. and Konstantinides S., Enhanced thrombosis in atherosclerosis-prone mice is associated with increased arterial expression of plasminogen activator inhibitor-1. Arterioscler. Thromb. Vas. Biol. 23: $2097-$ 2103, 2003.

18. Otterbein L.E., Zuckerbraun B.S., Haga M., Liu F., Song R., Usheva A., Stachulak C., Bodyak N., Smith R.N., Csizmadia E., Tyagi S., Akamatsu Y., Flavell R.J., Billiar T.R., Tzeng E., Bach F.H., Choi A.M. and Soares M.P., Carbon monoxide suppresses arteriosclerotic lesions associated with chronic graft rejection and with balloon injury. Nat. Med. 9: 183-190, 2003.

19. Tulis D.A., Durante W., Liu X., Evans A.J., Peyton K.J. and Schafer A.I., Adenovirus-mediated heme oxygenase-1 gene delivery inhibits injury-induced vascular neointima formation. Circulation 104: 2710-2715, 2001.

20. Lindenblatt N., Bordel R., Schareck W., Menger M.D. and Vollmar B., Vascular heme oxygenase-1 induction suppresses microvascular thrombus formation in vivo. Arterioscler. Thromb. Vas. Biol. 24: 106, 2004.

21. Hamsten A., DeFaire U., Walldius G., Dahlen G., Szamois A., Landou C., Blomback M. and Wiman B., Plasminogen activator inhibitor in plasma: risk factor for recurrent myocardial infarction. Lancet 2: 3-9, 1987.

22. Strauss B.H., Lau H.K., Bowman K.A., Sparkes J., Chisholm R.J., Garvey M.B., Fenkell L.L., Natarajan M.K.,
Singh I. and Teitel J.M., Plasma urokinase antigen and plasminogen activator inhibitor-1 antigen levels predict angiographic coronary restenosis. Circulation 100: 16161622,1999

23. Thogersen A.M., Jansson J.H., Boman K., Nilsson T.K., Weinehall L., Huhtasaari F. and Hallmans G., High plasminogen activator inhibitor and tissue plasminogen activator levels in plasma precede a first acute myocardial infarction in both men and women:evidence for the fibrinolytic system as an independent primary risk factor. Circulation 98: 2241-2247, 1998.

24. Schneiderman J., Sawdey M.S., Keeton M.R., Bordin G.M., Bernstein E.F., Dilley R.B. and Loskutoff D.J., Increased type 1 plasminogen activator inhibitor gene expression in atherosclerotic human arteries. Proc. Natl. Acad. Sci. USA 89: 6998-7002, 1992.

25. Kauhanen P., Siren V., Carpen O., Vaheri A., Lepantalo M. and Lassila R., Plasminogen activator inhibitor-1 in neointima of vein grafts:its role in reduced fibrinolytic potential and graft failure. Circulation 96: 1783-1789, 1997.

26. Hasenstab D., Forough R. and Clowes A.W., Plasminogen activator inhibitor type 1 and tissue inhibitor of metalloproteinases-2 increase after arterial injury in rats. Circ. Res. 80: 490-496, 1997.

27. Carmeliet P., Moons L., Lijnen R., Janssens S., Lupu F., Collen D. and Gerard R.D., Inhibitory role of plasminogen activator inhibitor-1 in arterial wound healing and neointima formation: a gene targeting and gene transfer study in mice. Circulation 96: 3180-3191, 1997.

28. Hasenstab D., Lea H. and Clowes A.W., Local plasminogen activator inhibitor type 1 overexpression in rat carotid artery enhances thrombosis and endothelial regeneration while inhibiting intimal thickening. Arterioscler. Thromb. Vas. Biol. 20: 853-859, 2000.

29. Zhu Y., Farrehi P.M. and Fay W.P., Plasminogen activator inhibitor type 1 enhances neointima formation after oxidative vascular injury in atherosclerosis-prone mice. Circulation 103: 3105-3110, 2001.

30. Degan J.L., Hemostatic factors and inflammatory disease. Thromb. Haemost. 82: 858-864, 1999. 